\title{
Functional Communication Profile-Revised: Application and Comparison with the Functional Communicative Profile-Checklist
}

\author{
Thaís Helena Ferreira Santos, Cibelle Albuquerque de la Higuera Amato, \\ Fernanda Dreux Miranda Fernandes
}

School of Medicine, Universidade de São Paulo, São Paulo, Brasil

Email: cibelleamato@usp.br

Received 12 June 2014; revised 6 July 2014; accepted 1 August 2014

Copyright (C) 2014 by authors and Scientific Research Publishing Inc.

This work is licensed under the Creative Commons Attribution International License (CC BY). http://creativecommons.org/licenses/by/4.0/

(c) (i) Open Access

\begin{abstract}
Assessment techniques regarding language and communication abilities of children with ASD must focus on functional communication and are essential to the assessment of the intervention proposals outcomes. The purpose of this study is to compare the results of two different protocols that assess the functional communicative profile. Participants were 50 children and adolescents with ages between 3 years 9 months and 14 years 8 months of both genders with diagnosis within the ASD. They were assessed by FCP-Rr and FCP-C. The results showed that although both instruments didn't result in equivalent data, they provided important information about the communication of children and adolescents with ASD because they used the same paradigms of analysis. The comparison of FCP-C and the FCP-Rr results in important information to the comprehensive understanding of children and adolescents with ASD because they use the same paradigms of variable analysis. Results also indicate that disorders in receptive language interfere directly in the interpersonal communication of these subjects while only severe disorders of expressive communication have significant effects on interpersonal communication.
\end{abstract}

\section{Keywords}

Autistic Disorder, Speech, Language and Hearing Sciences, Child Language, Functional Communication Profile, Questionnaires

\section{Introduction}

Since the first descriptions of autism by (Kanner, 1943) several studies have been conducted with the purpose of

How to cite this paper: Santos, T. H. F., de la Higuera Amato, C. A., \& Fernandes, F. D. M. (2014). Functional Communication Profile-Revised: Application and Comparison with the Functional Communicative Profile-Checklist. Psychology, 5, 13841391. http://dx.doi.org/10.4236/psych.2014.511149 
identifying and describing each subject's characteristics and propose more efficient intervention procedures.

Autism is classified as a Pervasive Developmental Disorder on the DSM 5, and is described by the American Psychiatric Association as a complex group of disorders in the areas of social communication and social cognition (APA, 2013).

The central role of language is probably one of the few agreement points in all descriptions of autism (Fernandes, 2000). The functional perspective of language use takes into account, besides the functions and communicative means, the context in which communication happens. It shows that considering the non-verbal aspects of communication is essential to its comprehensive assessment (Emerson, 2001).

The difficulties in communication occur in varying degrees, both in verbal and non-verbal ability of sharing information with others. Some children don't develop communication abilities. Other children present an immature language, characterized by the use of jargon, echolalia, pronoun reversal, abnormal prosody, monotonous tone of voice and other disorders. The language and communication deficits tend to persist through adulthood (Gadia et al., 2004). Those individuals that acquire verbal abilities can show persistent deficits in their capacity to establish and maintain conversation. These difficulties can manifest as lack of reciprocity, difficulties to understand language subtleties, jokes and sarcasm, as well as problems to understand body language and facial expressions

Language as a communicative mean between people has systematic rules that are used to convey thoughts and cooperate in social interactions (Bess \& Humes, 1998). The systematic assessment of communicative competence includes a clear understanding of the contexts where the child uses his/her linguistic abilities.

Assessment techniques must focus on the differential diagnosis and the functional communication development. Determining standard evaluation criteria is essential to the assessment of intervention proposals (Fernandes, 2003).

The speech-language pathologist must assess the association of language abilities and communicative competence of children with ASD. Language ability refers to the child's capacity to understand and formulate spoken or written symbolic systems. Communicative competence refers to the capacity to use language as an interactive tool in different social contexts regardless of the communicative means used (Bara et al., 2001).

Used to assess communication, the Functional Communicative Profile-Revised (FCP-R) provides a sensible and organized method to the assessment of individual communicative abilities according to their age and acquired or developmental deficits (Kleiman, 2003).

The purpose of this study is to propose a reduced instrument based on the FCP-R and compare its results with those obtained with the Functional Communicative Profile-Checklist (FCP-C).

\section{Methods}

Participants were 50 children and adolescents with ages between 3 years 9 months and 14 years 8 months of both genders with diagnosis within the ASD. All attended speech-language therapy at a specialized service at a University clinic for at least 6 months and for no more than 2 years.

They were assessed by:

- FCP-Rr-a reduced protocol based on the FCP-R (developed by the authors) that comprises the areas of Behavior, Attention, Receptive Language, Expressive Language and Social/Pragmatics. This instrument was applied during an interview with the speech-language therapists. The scoring system was adapted, with a proportion analysis, from the original suggested by Santos \& Fernandes (2012). The protocol was applied as an interview with the therapists. The questions included in the reduced version were the ones considered the most appropriate to the Brazilian reality and the ones identified as the most relevant of the complete form.

- FCP-C—a list of communicative functions expressed by the participants, also applied during an interview with the speech-language pathologist. It considers 20 communicative functions, their frequency-as always (A), many times (MT), rarely (R) or never $(\mathrm{N})$-and the communicative means used to express them-as Verbal (VE), Vocal (VO) and Gestual (G). The communicative functions were divided in two groups: more interpersonal and less interpersonal for the analysis of PFC-C according Cardoso \& Fernandes (2003). The percentage of occurrence of communicative functions was obtained through every assigned possible occurrence (A, MT, R, N) and the communicative mean was calculated for each communicative function (only were considered the communicative functions that effectively occurred, regardless of the amount-A, MT and $\mathrm{R}$ ) for both more and less interpersonal functions. From the percentages of occurrence, the communication 
interactiveness was determined by the proportion of communicative acts with interpersonal functions expressed.

The obtained data from FCP-Rr and FCP-C were characterized through descriptive analysis. This data were compared individually by t-Student test and the significant level adopted was 0.05 (5\%). The correlation test was conducted in order to verify linear correlations.

The data relating to the frequency of the communicative acts with interpersonal functions obtained in FCP-C were analyzed according to their averages, separated by domain and then by degree of severity according to the FCP-Rr.

\section{Results and Discussion}

The data obtained in the FCP-Rr are described in Figure 1 and its analysis presented thereafter.

The results indicate that in the Behavior domain the moderate classification was representative for the studied population. For the Attentiveness domain, the more prevalent classifications were mild and moderate. To the Receptive Language domain the classification comprehended between regular and mild was considered representative of this domain.

To the Expressive Language, the classifications with higher prevalence were: mild, moderate and severe (respectively). Thus, it is possible to state that the mild classification for the Expressive Language domain is representative for the studied population; however, the answers varies between mild, moderate and severe, being this classification of variation (light to severe) representative for this domain. For the Pragmatic/Social domain, the severe classification is considered significant regarding the others.

Data obtained in the FCP-C are described at Figure 2 and Figure 3.

The data obtained in the FCP-C showed that "many times" is the classification with higher prevalence to the more interpersonal functions although the occurrence for other classifications is also prevalent. The preferred mean of communication to this population was gestural.

The descriptive statistical analysis of FCP-C is presented at Table 1.

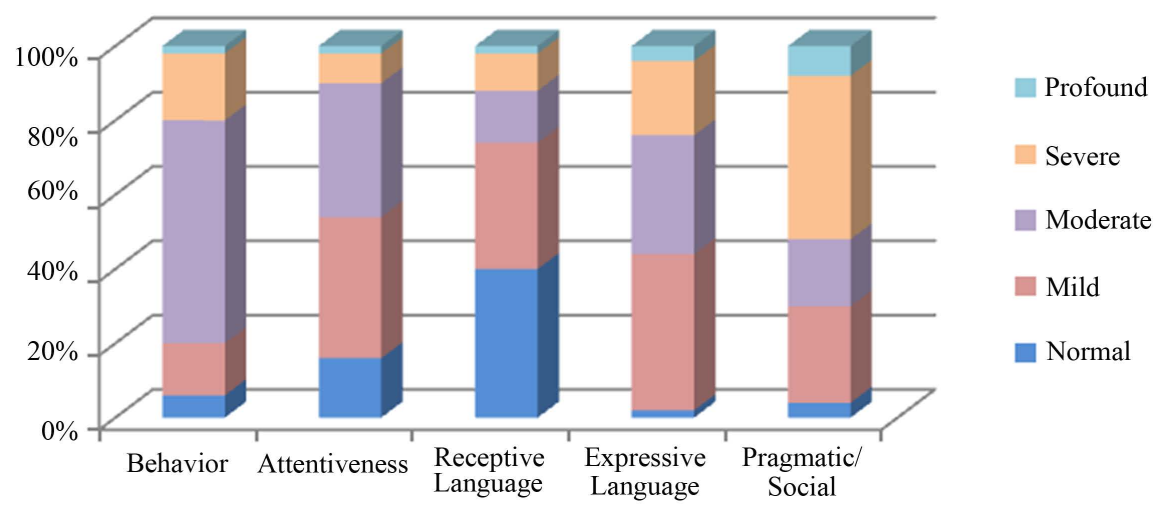

Figure 1. Proportional distribution of the answers on the FCP-Rr domains.

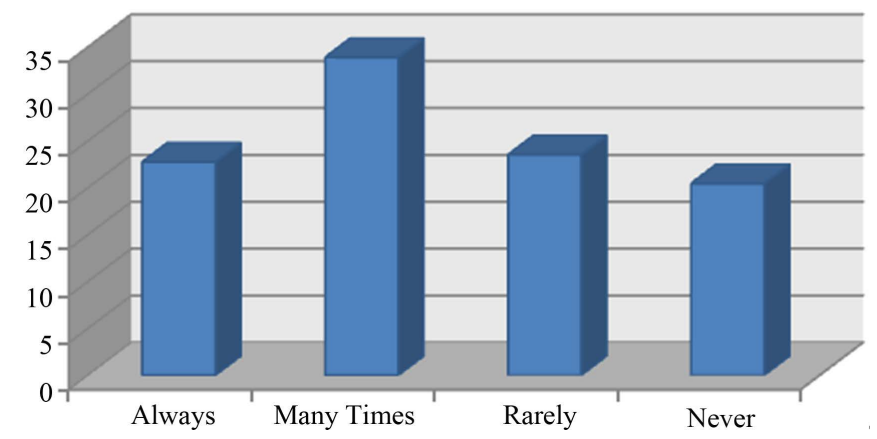

Figure 2. Mean distribution regarding the frequency to the more interpersonal functions. 


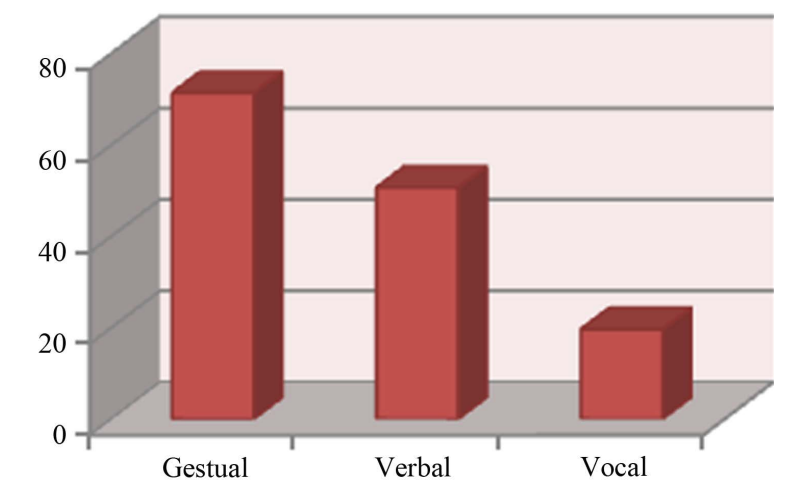

Figure 3. Mean distribution regarding the communicative means to the more interpersonal functions.

Table 1. Descriptive statistic of PFC-C.

\begin{tabular}{cc}
\hline Mean & 65.14 \\
\hline Standard deviation & 0.85 \\
Median & 65 \\
Standard deviation & 6.02 \\
Variance & 36.2 \\
\hline
\end{tabular}

To conduct the comparison of a population that presents variable data is a challenge that, sometimes, can show conflicting results. In this study, to minimize this effect we used the median (65\%) as a pattern of interactivity presented by this group. Thus, the individuals above $65 \%$ of interactivity were considered more interactive.

Table 2 presents the data distribution of interactivity.

The comparison between the data of PFC-Rr and the data obtained from the proportion of interactivity in FCP-C are in the following tables and it's analysis presented thereafter.

The comparison of the Behavior domain of the FCP-Rr and the FCP-C resulted in a negative association suggesting that as the severity of the behavior disorder increases the communicative interaction, as assessed by the FCP-C, decreases. Therefore, Behavior seems to interfere in communication interaction. The results were similar in the Attentiveness domain, revealing evidence of the interference among different areas (Table 3).

In the Receptive Language domain of the FCP-Rr, besides a clear interference of the communication interaction there was a clear heterogeneity among subjects. It was shown that even the slightest disorder in receptive language may interfere with communicative interaction. A study that analyzed the pragmatic, vocabulary and grammatical abilities of children with ASD (Miilher \& Fernandes, 2009) also pointed out to the important role of language to the social interaction of these individuals (Table 4).

However, there seems to be direct interference of Expressive Language only if the disorder is characterized as severe. Wetherby, Prizant, \& Schuler (2000) have shown a strong association of joint attention abilities and communicative reciprocity with expressive language, agreeing with the present study. There were no linear associations with the Pragmatic/Social domain between the FCP-C and the FCP-Rr, thus confirming the proximity of the protocols (Table 5 and Table 6).

The frequency of the more interactive functions observed by the FCP-C seems to be directly related to the major difficulties in attention/concentration, receptive and expressive language, pragmatic and social abilities of individuals with ASD. Other studies (Mundy \& Neal, 2000; Jones \& Carr, 2004; Tierney et al., 2012, Varanda \& Fernandes, 2011) point out to the relevance of attention, concentration and language abilities to the social development of ASD individuals (Table 7).

The association between PFC-C and FCP-Rr is presented in Figure 4.

Studies (Farah, Perissionoto, \& Chiari, 2009; Lord, 2000) indicate that the severity of autism directly affects the evolution of communicative processes of autistic individuals. Thus, identification of the severity may contribute to the understanding of the therapeutic processes. 
Table 2. Data distribution of interactivity from the median.

\begin{tabular}{ccc}
\hline More interpersonal & Less interpersonal & $p$-value \\
\hline $60 \%$ & $40 \%$ & $0.0006^{*}$ \\
\hline
\end{tabular}

${ }^{*}$ Significant difference- $-\mathrm{t}$-student test- $5 \%$.

Table 3. Association between behavior domain of FCP-Rr and the proportion of interactivity of FCP-C.

\begin{tabular}{|c|c|c|c|c|c|c|c|c|c|c|}
\hline Severity & \multicolumn{2}{|c|}{ Normal } & \multicolumn{2}{|c|}{ Mild } & \multicolumn{2}{|c|}{ Moderate } & \multicolumn{2}{|c|}{ Severe } & \multicolumn{2}{|c|}{ Profound } \\
\hline Behavior & \multicolumn{2}{|c|}{$6 \%$} & \multicolumn{2}{|c|}{$14 \%$} & \multicolumn{2}{|c|}{$60 \%$} & \multicolumn{2}{|c|}{$18 \%$} & \multicolumn{2}{|c|}{$2 \%$} \\
\hline \multirow[t]{2}{*}{ Interactivity } & More & Less & More & Less & More & Less & More & Less & More & Less \\
\hline & 3 & 0 & 6 & 1 & 18 & 12 & 2 & 7 & 0 & 1 \\
\hline$p$-value & \multicolumn{2}{|c|}{0.27} & \multicolumn{2}{|c|}{$0.004^{*}$} & \multicolumn{2}{|c|}{$0.009^{*}$} & \multicolumn{2}{|c|}{$0.008^{*}$} & \multicolumn{2}{|c|}{0.72} \\
\hline Correlation coefficient & & & & & \multicolumn{2}{|c|}{-0.11187} & & & & \\
\hline
\end{tabular}

*Significant data-t-student test.

Table 4. Association between attentiveness domain of FCP-Rr and the proportion of interactivity of FCP-C.

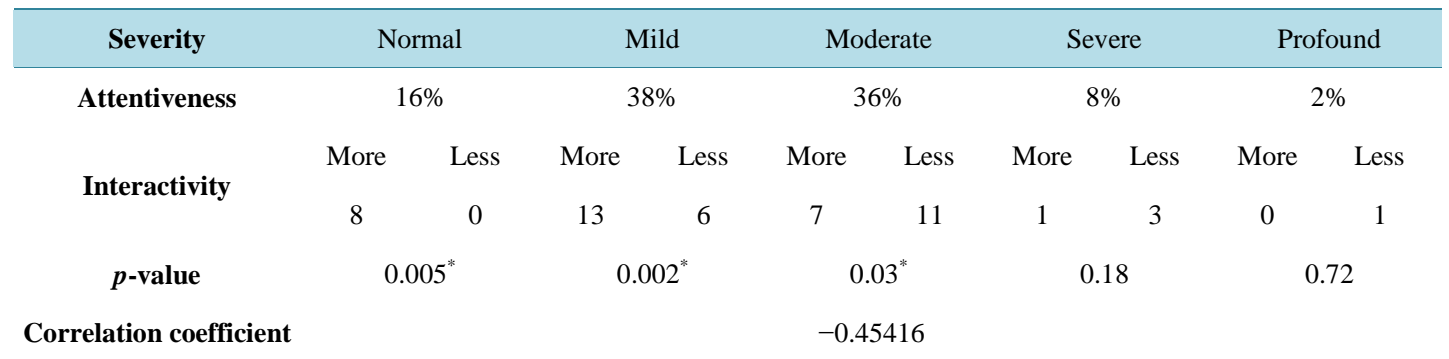

*Significant data—-t-student test.

Table 5. Association between receptive language domain of FCP-Rr and the proportion of interactivity on FCP-C.

\begin{tabular}{|c|c|c|c|c|c|c|c|c|c|c|}
\hline Severity & \multicolumn{2}{|c|}{ Normal } & \multicolumn{2}{|c|}{ Mild } & \multicolumn{2}{|c|}{ Moderate } & \multicolumn{2}{|c|}{ Severe } & \multicolumn{2}{|c|}{ Profound } \\
\hline Receptive language & \multicolumn{2}{|c|}{$40 \%$} & \multicolumn{2}{|c|}{$34 \%$} & \multicolumn{2}{|c|}{$14 \%$} & \multicolumn{2}{|c|}{$10 \%$} & \multicolumn{2}{|c|}{$2 \%$} \\
\hline \multirow{2}{*}{ Interactivity } & More & Less & More & Less & More & Less & More & Less & More & Less \\
\hline & 17 & 3 & 6 & 11 & 5 & 2 & 1 & 4 & 0 & 1 \\
\hline$p$-value & \multicolumn{2}{|c|}{$<0.001^{*}$} & \multicolumn{2}{|c|}{$0.01^{*}$} & \multicolumn{2}{|c|}{0.07} & \multicolumn{2}{|c|}{0.06} & \multicolumn{2}{|c|}{0.72} \\
\hline Correlation coefficient & & & & & \multicolumn{2}{|c|}{-0.68858} & & & & \\
\hline
\end{tabular}

${ }^{*}$ Significant data—-t-student test.

Table 6. Association between expressive language domain of FCP-Rr and the proportion of interactivity on FCP-C.

\begin{tabular}{|c|c|c|c|c|c|c|c|c|c|c|}
\hline Severity & \multicolumn{2}{|c|}{ Normal } & \multicolumn{2}{|c|}{ Mild } & \multicolumn{2}{|c|}{ Moderate } & \multicolumn{2}{|c|}{ Severe } & \multicolumn{2}{|c|}{ Profound } \\
\hline Expressive & \multicolumn{2}{|c|}{$2 \%$} & \multicolumn{2}{|c|}{$42 \%$} & \multicolumn{2}{|c|}{$32 \%$} & \multicolumn{2}{|c|}{$20 \%$} & \multicolumn{2}{|c|}{$4 \%$} \\
\hline \multirow[t]{2}{*}{ Interactivity } & More & Less & More & Less & More & Less & More & Less & More & Less \\
\hline & 1 & 0 & 13 & 5 & 9 & 7 & 2 & 8 & 1 & 1 \\
\hline$p$-value & \multicolumn{2}{|c|}{0.72} & \multicolumn{2}{|c|}{$<0.001^{*}$} & \multicolumn{2}{|c|}{0.16} & \multicolumn{2}{|c|}{$0.002^{*}$} & \multicolumn{2}{|c|}{1} \\
\hline Correlation coefficient & \multicolumn{10}{|c|}{0.11216} \\
\hline
\end{tabular}

${ }^{*}$ Significant data—-t-student test. 
Table 7. Association between pragmatic/social domain of FCP-Rr and the proportion of interactivity on FCP-C.

\begin{tabular}{|c|c|c|c|c|c|c|c|c|c|c|}
\hline Severity & \multicolumn{2}{|c|}{ Normal } & \multicolumn{2}{|c|}{ Mild } & \multicolumn{2}{|c|}{ Moderate } & \multicolumn{2}{|c|}{ Severe } & \multicolumn{2}{|c|}{ Profound } \\
\hline Pragmatic/Social & \multicolumn{2}{|c|}{$4 \%$} & \multicolumn{2}{|c|}{$26 \%$} & \multicolumn{2}{|c|}{$18 \%$} & \multicolumn{2}{|c|}{$44 \%$} & \multicolumn{2}{|c|}{$8 \%$} \\
\hline \multirow[t]{2}{*}{ Interactivity } & More & Less & More & Less & More & Less & More & Less & More & Less \\
\hline & 2 & 0 & 11 & 2 & 5 & 4 & 11 & 11 & 0 & 4 \\
\hline$p$-value & \multicolumn{2}{|c|}{0.46} & \multicolumn{2}{|c|}{$<0.001^{*}$} & \multicolumn{2}{|c|}{0.37} & \multicolumn{2}{|c|}{1} & \multicolumn{2}{|c|}{0.14} \\
\hline Correlation coefficient & \multicolumn{10}{|c|}{0.00328} \\
\hline
\end{tabular}

*Significant data—-t-student test.

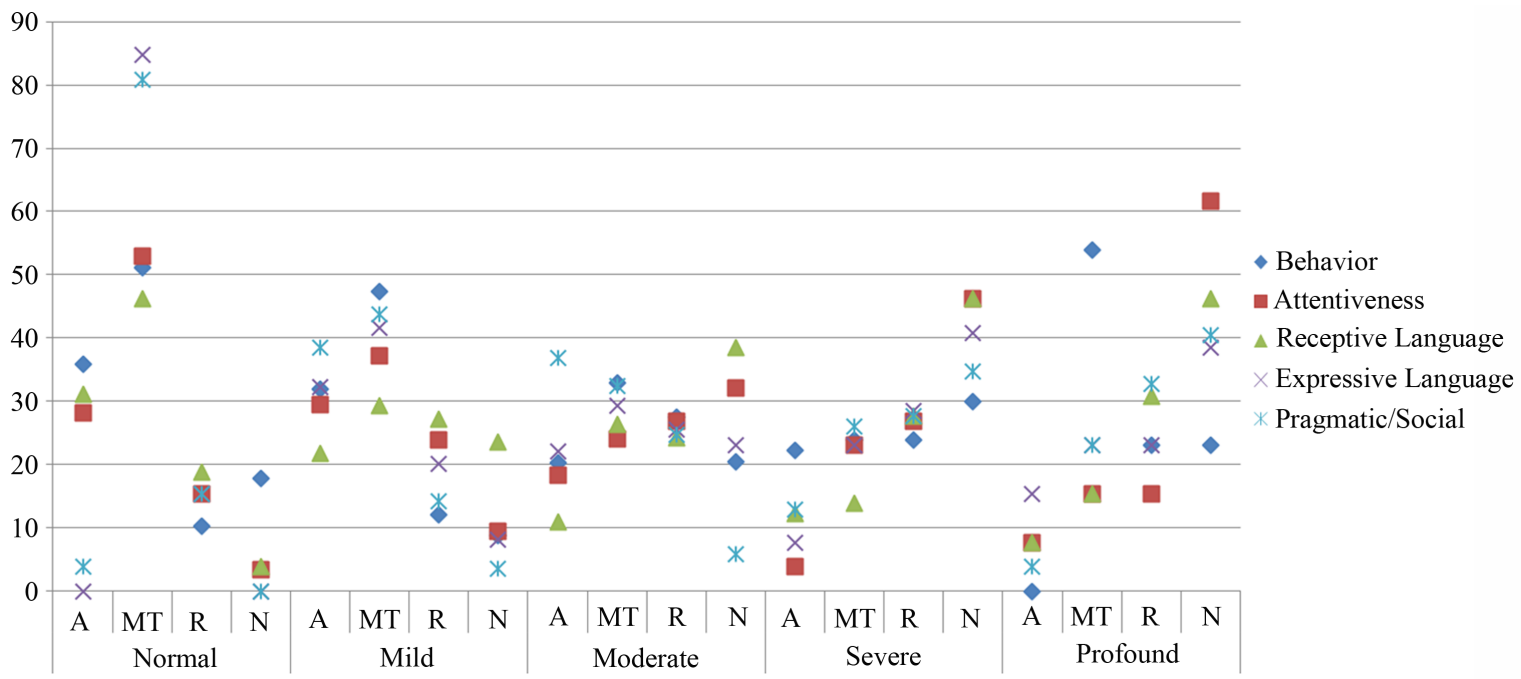

Figure 4. Distribution of the interactivity proportion of FCP-C regarding the classification on FCP-Rr domains average.

The use of objective protocols in the clinical practice not always had been systematic; gradually the need for insertion of these tools in the practice of Brazilian Speech Language Pathologist was observed (Marchesan, 2003). References in the area of language also highlight the importance of using objective instruments (Wertzner, Amaro, \& Teramoto, 2005, Cardoso \& Fernandes, 2006) for assessing and monitoring the clinical outcomes. Besides greater reliability of the obtained data, the importance of systematically evaluating and measuring progress of patients throughout the therapeutic process is evident.

Because of the phenotypic variation, often the protocols fail to provide accurate records of individuals in the autism spectrum. Its implementation and critical evaluation as complementary to other forms of analysis can bring good parameters to the assessment of individual characteristics. It also allow individuals to be compared with themselves over time or in different situations, providing useful information to therapeutic decisions and scientific research. Many studies have used this parameter - the subject as its own control (Moreira \& Fernandes, 2010; Fernandes et al., 2010; Windholz, 1995).

To differeciate the autism spectrum disorders, the severity in language deficits is very important. Currently in Brazil, although we can count with important contributions (Andrade, Befi-Lopes, Fernandes, \& Wertzner, 2000; Zorzi \& Hage, 2004), there is still a lack of formal and objective instruments that are commercially available and appropriate to the language assessment and diagnosis (Velloso et al., 2011).

The use of objective protocols is very important to Speech Language clinic with autism spectrum disorders, but should be used with criticism and individually.

\section{Conclusion}

The results show that the comparison of FCP-R and PFC-C doesn't result in equivalent data since they have different approaches. The FCP-C provides a detailed review of the use of language regarding to the occurrence, 
frequency and use, bringing quantitative impressions of the language characteristics of individuals with autism. However, the FCP-R only considers the occurrence of the communicative acts, regardless of the situation in which they are expressed. It is observed that the areas of formal language and interactivity are interrelated; another important factor to consider while planning therapeutic procedures.

The comparison of FCP-C and the FCP-Rr results in important information to the comprehensive understanding of children and adolescents with ASD because they use the same paradigms of variable analysis. Results indicate that disorders in receptive language interfere directly in the interpersonal communication of these subjects while only severe disorders of expressive communication have significant effects on interpersonal communication.

\section{References}

American Psychiatry Association (2013) Diagnostic and Statistical Manual of Mental Disorders (5th ed.). Arlington, VA: American Psychiatry Publishing.

Andrade, C. R. F., Befi-Lopes, D. M., Fernandes, F. D. M., \& Wertzner, H. F. (2000). ABFW-Teste de Linguagem Infantil. Carcapicuíba: Pró-Fono.

Bara, B. G., Bucciarelli, M., \& Colle, L. (2001) Communicative Abilities in Autism: Evidence for Attencional Deficits. Brain and Language, 77, 216-240. http://dx.doi.org/10.1006/brln.2000.2429

Bess, F., \& Humes, L. (1998) Patologias do sistema auditivo. In Fundamentos da audiologia (pp. 159-194). Porto Alegre: Artmed.

Cardoso, C., \& Fernandes, F. D. (2006). Relação entre os aspectos sócio cognitivos e perfil funcional da comunicação em um grupo de adolescentes do espectro autístico. Pró-Fono Revista de Atualização Científica, 18, 89-98. http://dx.doi.org/10.1590/S0104-56872006000100011

Cardoso, C., \& Fernandes, F. D. M. (2003). Terapia de linguagem com crianças do espectro autístico: Comparação entre dois modelos de atendimento. Temas sobre Desenvolvimento, 11, 34-38.

Emerson, E. (2001) Mothers of Children and Adolescent with Intellectual Disabilities: Social and Economic Situation, Mental Health Status and Self-Assessed Social and Psychological Impact of Child's Difficulties. Journal of Intellectual Disability Research, 47, 385-396.

Farah, L. S. D., Perissinoto, J., \& Chiari, B. M. (2009). Estudo longitudinal da atenção compartilhada em crianças autistas não verbais. Revista CEFAC, 11, 587-597. http://dx.doi.org/10.1590/S1516-18462009000800007

Fernandes, F. D. (2003). Distúrbios da linguagem em autismo infantil. In S. C. Limongi (Ed.), Fonoaudiologia informação para a formação: Linguagem: Desenvolvimento normal. Alterações e distúrbios (pp. 65-86). Rio de Janeiro: Guanabara Koogan.

Fernandes, F. D. (2000). Aspectos funcionais da comunicação de crianças autistas. Temas sobre Desenvolvolvimento, 9, 2535.

Fernandes, F. D. M., Santos, T. H. F., Amato, C. A. H., \& Molini-Avejonas, D. R. (2010). Recursos de informática na terapia fonoaudiológica de crianças do espectro autístico. Pró-Fono Revista de Atualização Científica, 22, 415-420.

Gadia, C., Tuchman, R., \& Rotta, N. T. (2004). Autismo e doenças invasivas de desenvolvimento. Jornal de Pediatria, 80, 83-94. http://dx.doi.org/10.1590/S0021-75572004000300011

Jones, E. A., \& Carr, E. G. (2004). Joint Attention in Children with Autism: Theory and Intervention. Focus on Autism and Developmental Disabilities, 19, 13-26. http://dx.doi.org/10.1177/10883576040190010301

Kanner, L. (1943). Affetive Disturbances of Affective Contact. Nervous Child, 2, 217-250.

Kleiman, L. I. (2003). Functional Communication Profile Revised. Austin: Lingui Systems.

Lord, C. (2000). Commentary: Achievements and Future Directions for Intervention in Communication and Autism Spectrum Disorders. Journal of Autism and Developmental Disorders, 30, 393-398. http://dx.doi.org/10.1023/A:1005591205002

Marchesan, I. Q. (2003). Protocolo de Avaliação Miofuncional Orofacial. In H. L. Krakauer, R. Francesco, \& I. Q. Marchesan (Eds.), Respiração Oral. Coleção CEFAC (pp. 55-79). São José dos Campos: Pulso.

Miilher, L. P., \& Fernandes, F. D. M. (2009). Habilidades pragmáticas, vocabulares e gramaticais em crianças com transtornos do espectro autístico. Pró-Fono Revista de Atualização Científica, 21, 309-314.

Moreira, C. R., \& Fernandes, F. D. (2010). Assessing Communication in the Autistic Spectrum: Interference of Familiarity in Language Performance. Revista da Sociedade Brasileira de Fonoaudiologia, 15, 430-435.

Mundy, P., \& Neal, A. R. (2000). Neural Plasticity, Joint Attention, and a Transactional Social-Orienting Model of Autism. International Review of Research in Mental Retardation, 23, 139-168. 
Santos, T. H. F., \& Fernandes, F. D. M. (2012). Functional Communication Profile-Revised: Objective Description of Children and Adolescents of the Autism Spectrum. Revista da Sociedade Brasileira de Fonoaudiologia, 17, 454-458.

Tierney, C. D., Gupta, V. B., Angel, A. P., \& Augustyn, M. (2012). Teasing out Specific Language Impairment from an Autism Spectrum Disorder. Journal of Developmental and Behavioral Pediatrics, 33, 272-274. http://dx.doi.org/10.1097/DBP.0b013e31824ea235

Varanda, C. A., \& Fernandes, F. D. M. (2011). Syntactic Awareness: Probable Correlations with Central Coherence and Non-Verbal Intelligence in Autism. Jornal da Sociedade Brasileira de Fonoaudiologia, 23, 142-151.

Velloso, R. L., Vinic, A. A., Duarte, C. P., Dantino, M. E. F., Brunoni, D., \& Schwartzman, J. S. (2011). Protocolo de avaliação diagnóstica multidisciplinar da equipe de transtornos globais do desenvolvimento vinculado à pós graduação em distúrbios do desenvolvimento da universidade presbiteriana Mackenzie. Cadernos de Pós-Graduação em Distúrbios do Desenvolvimento, 11, 9-22.

Wertzner, H. F., Amaro, L., \& Teramoto, S. S. (2005). Gravidade do distúrbio fonológico: Julgamento perceptivo e porcentagem de consoantes corretas. Pró-Fono Revista de Atualização Científica, 17, 185-194. http://dx.doi.org/10.1590/S0104-56872005000200007

Wetherby, A. M., Prizant, B. M., \& Schuler, A. L. (2000). Understanding the Nature of Communication and Language Impairments. In M. Wetherby, \& B. M. Prizant (Eds.), Autism Spectrum Disorders: A Transactional Developmental Perspective (pp. 109-141). Baltimore, MD: Brookes.

Windholz, G. (1995). Pavlov's Position on Old Age within the Framework of the Theory of the Higher Nervous Activity. International Journal of Aging and Human Development, 40, 75-88.

Zorzi, J. L., \& Hage, S. R. V. (2004). PROC Protocolo de observação: Avaliação de linguagem e aspectos cognitivos infantis. São José dos Campos: Pulso. 
Scientific Research Publishing (SCIRP) is one of the largest Open Access journal publishers. It is currently publishing more than 200 open access, online, peer-reviewed journals covering a wide range of academic disciplines. SCIRP serves the worldwide academic communities and contributes to the progress and application of science with its publication.

Other selected journals from SCIRP are listed as below. Submit your manuscript to us via either submit@scirp.org or Online Submission Portal.
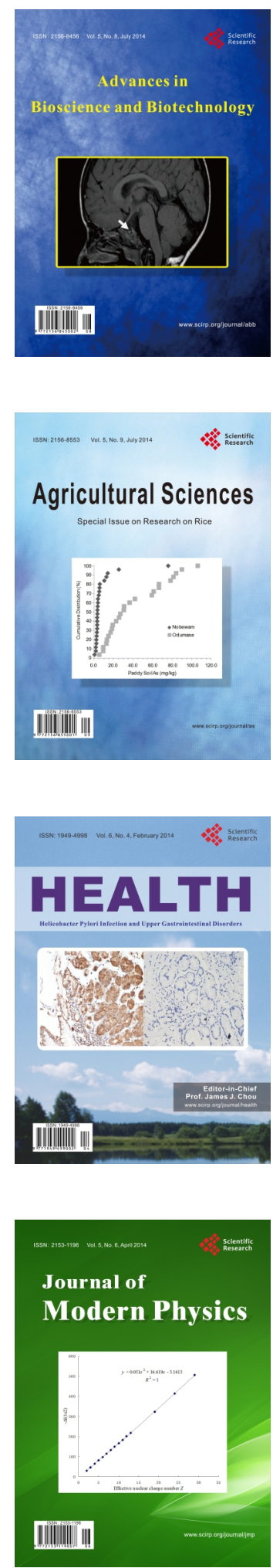
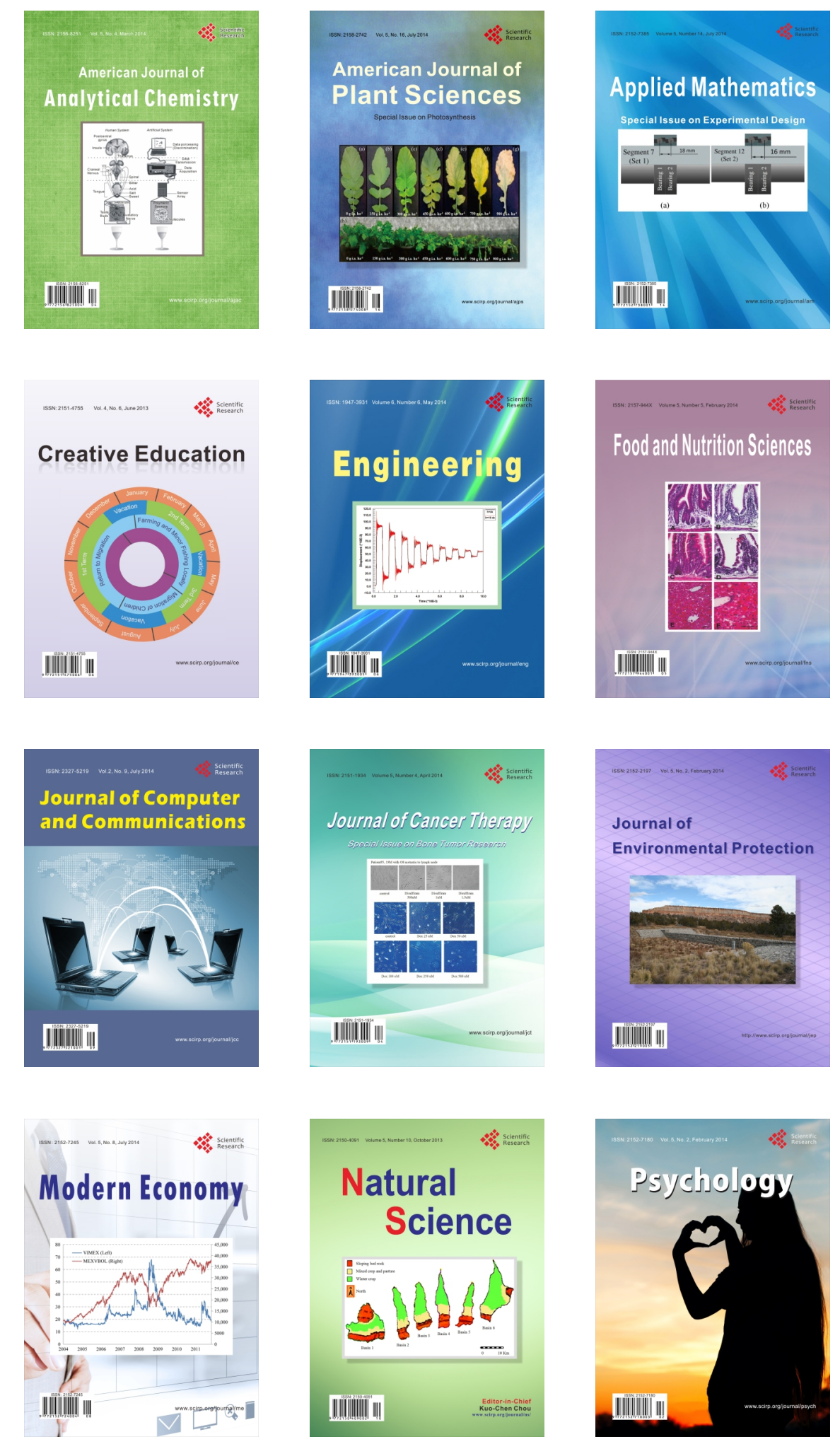